\title{
3D GEO: AN ALTERNATIVE APPROACH
}

\author{
A. Georgopoulos* \\ Laboratory of Photogrammetry \\ School of Rural \& Surveying Engineering \\ National Technical University of Athens, Greece \\ drag@central.ntua.gr
}

KEY WORDS: Digitization of Cultural Heritage, 3D modelling, Geometric Documentation, Cultural Heritage Management

\begin{abstract}
:
The expression GEO is mostly used to denote relation to the earth. However it should not be confined to what is related to the earth's surface, as other objects also need three dimensional representation and documentation, like cultural heritage objects. They include both tangible and intangible ones. In this paper the 3D data acquisition and 3D modelling of cultural heritage assets are briefly described and their significance is also highlighted. Moreover the organization of such information, related to monuments and artefacts, into relational data bases and its use for various purposes, other than just geometric documentation is also described and presented. In order to help the reader understand the above, several characteristic examples are presented and their methodology explained and their results evaluated.
\end{abstract}

\section{INTRODUCTION}

\subsection{D GEO}

GEO is usually expressing whatever has some relation to the surface of our planet. But is it really so? It could alternatively be interpreted as an acronym Ground-Earth-Object. This interpretation is more general and more suitable to include and imply the whole range of today's applications of Geomatics. Consequently, GEOinformation may be broadly seen as the discipline which records the Ground, the Earth and the Objects and assigns information to them. In that sense 3D GEO implies three dimensional recording of all possible objects including Cultural Heritage assets, irrelevantly if they are movable or immovable.

\subsection{D Objects}

Nowadays, rapid technological advances have enabled many experts to produce and work with three-dimensional information about the objects under investigation. This information may be visualized virtually on a computer screen or even be printed at a scale via a $3 \mathrm{D}$ printer. This evolvement has definitely enabled better studies as the experts can now grasp the object in 3D space. Especially in Cultural Heritage applications 3D digital models are gaining in usability not only for visualization purposes, as will be shown later.

\section{GEOMETRIC DOCUMENTATION OF CULTURAL HERITAGE OBJECTS}

Monuments, including immovable structures of any kind and movable artifacts, are undeniable documents of world history. Their thorough study is an obligation of our era to mankind's past and future. Respect towards cultural heritage has its roots already in the era of the Renaissance. During the 19th century archaeological excavations became common practice, while they matured in the 20th century. Over the recent decades, international bodies and agencies have passed resolutions concerning the obligation for protection, conservation and restoration of monuments. The Athens Convention (1931), the Hague Agreement (1954), the Charter of Venice (1964) and the Granada Agreement (1985) are some of these resolutions in which the need for the full documentation of the monuments is also stressed, as part of their protection, study and conservation. Nowadays, most countries of the civilized world are using their scientific and technological efforts towards protecting and conserving the monuments within or even outside their borders assisting other countries. These general tasks include geometric recording, risk assessment, monitoring, restoring, reconstructing and managing Cultural Heritage.

\subsection{Definition}

The integrated documentation of monuments includes the acquisition of all possible data concerning the monument and which may contribute to its safeguarding in the future. Such data may include historic, archaeological, architectural information, but also administrative data and past drawings, sketches, photos etc. Moreover these data also include metric information which defines the size, the form and the location of the monument in $3 \mathrm{D}$ space, which document the monument geometrically.

The geometric documentation of a monument, which should be considered as an integral part of the greater action, the Integrated Documentation of Cultural Heritage may be defined as (UNESCO, 1972):

- The action of acquiring, processing, presenting and recording the necessary data for the determination of the position and the actual existing form, shape and size of a

\footnotetext{
* Corresponding author
} 
monument in the three dimensional space at a particular given moment in time.

- The geometric documentation records the present of the monuments, as this has been shaped in the course of time and is the necessary background for the studies of their past, as well as the care of their future.

The geometric documentation of a monument consists of a series of necessary measurements, from which visual products such as vector drawings, raster images, 3D visualizations etc. may be produced at small or large scales. These products have usually metric properties, especially those being in suitable orthographic projections. Hence one could expect from the geometric documentation a series of drawings, which actually present the orthoprojections of the monument on suitably selected horizontal or vertical planes. Very important properties of these products are their scale and accuracy. These should be carefully defined at the outset, before any action on the monument.

\subsection{Methodology}

For the geometric recording several surveying methods may be applied, ranging from the conventional simple topometric methods, for partially or totally uncontrolled surveys, to the elaborated contemporary surveying and photogrammetric ones, for completely controlled surveys. The simple topometric methods are applied only when the small dimensions and simplicity of the monument may allow it, when an uncontrolled survey is adequate, or in cases when a small completion of the fully controlled methods is required.

Surveying and photogrammetric methods are based on direct measurements of lengths and angles, either on the monument or on images thereof. They determine three-dimensional point coordinates in a common reference system and ensure uniform and specified accuracy. Moreover they provide adaptability, flexibility, speed, security and efficiency. All in all they present undisputed financial merits, in the sense that they are the only methods, which may surely meet any requirements with the least possible total cost and the biggest total profit. To this measurement group belong the terrestrial laser scanners (TLS). They manage to collect a huge number of points in 3D space, usually called point cloud, in a very limited time frame.

It should, however, be stressed that, since up to date there is no generally acceptable framework for specifying the level of detail and the accuracy requirements for the various kinds of geometric recording of monuments, every single monument is geometrically documented on the basis of its own accuracy and cost specifications. Therefore it is imperative that all disciplines involved should cooperate closely, exchange ideas and formulate the geometric documentation requirements in common, while they deeply understand the monument itself and each other's needs.

\subsection{D Digitization}

Common practice in taking care of the World's Cultural Heritage starts right from the initial historical studies and the thorough consultation of literature and written or other sources. It is then followed by an extensive bibliographic documentation from previous excavations and published studies in a particular area. Theoretical studies are then followed by the main archaeological research, which includes exploratory field research, excavation research, structural archaeological research and landscape archaeological activities. These in situ activities initiate the thorough study and processing of the archaeological material discovered in conjunction with related publications. This leads then to protection and management actions, either for extended archaeological sites or for archaeological finds. The culmination of archaeological practice is the actions of conservation of the material and of course the publication of the results. The introduction of Digital Technologies may contribute to all of the above traditional steps. By "contribution" here is by no means meant "replacement", but "enhancement" and "support". It goes without saying that the degree of contribution of Information Communication Technologies (ICT) is different in the various stages and in the various cases.

The initial historical studies will benefit from the expansion and operation of the digital libraries. Practically all related bibliography is readily available via a simple search engine and a standard computer. Modern technologies of remote sensing assist the touchless and rapid detection of objects of interest. Spectroradiometers or ground penetrating radars or even the simple processing of multispectral satellite images, may easily lead to the rapid location of underground or submerged objects of interest. Contemporary survey technologies, such as photogrammetry, terrestrial laser scanning and digital imaging, may be used to produce accurate base maps for further study, or $3 \mathrm{D}$ virtual renderings and visualizations. The collected data may be stored in interactive databases, georeferenced or not, and managed according to the needs of the experts. Finally Information Communication Technologies (ICT) may assist in the presentation stage, by producing virtual models, which may be displayed in museum or be included in an educational DVD, or serve purposes of enabling handicapped persons to admire the treasures of the World's cultural heritage.

The use of Digital technologies in preservation and curation in general of cultural heritage is also mandated by UNESCO. With the Charter on the Preservation of the Digital Cultural Heritage this global organization proclaims the basic principles of Digital Cultural Heritage for all civilized countries of the world. At the same time numerous international efforts are underway with the scope to digitize all aspects of Cultural heritage, be it large monuments, or tangible artifacts or even intangible articles of the world's legacy (Stylianidis \& Remondino 2016).

\subsubsection{Technological Progress}

Nowadays, the rapid advances of Digital Technology also referred to as Information Communication Technologies (ICT), have provided scientists with new powerful tools. We are now able to acquire, store, process, manage and present any kind of information in digital form. This may be done faster, more completely and it may ensure that this information may be easily available for a larger base of interested individuals. Those digital tools include instrumentation for data acquisition, such as scanners, digital cameras, digital total stations etc., software for processing and managing the collected data and -of coursecomputer hardware, for running the software, storing the data and presenting them in various forms.

\subsubsection{Digital Instrumentation}

The instrumentation necessary to support heritage conservation activities should always be at the technological edge nowadays. Modern instrumentation includes data acquisition instruments, 
processing software and powerful computers. Data acquisition instruments should include devices which are capable of digitally collecting

- Images or image sequences

- $\quad$ Points in 3D space

- Other pieces of information related to Cultural Heritage objects

Rapid technological progress has provided scientists with sophisticated instrumentation, which includes calibrated high resolution digital cameras, digital high resolution video recorders, accurate angle and distance measuring devices, GPS receivers, terrestrial laser scanners, 3D non laser scanners for small artifacts, film scanners and printed document scanners. Moreover instrumentation such as thermal and range cameras, material sampling devices and ultrasonic non-destructive inspecting instruments are also contributing to data acquisition.

\subsubsection{Software}

Processing of all acquired multi-source data includes actions of position calculations, processing of the digital images or image sequences and working with point clouds. For these actions related software has been developed to cover all possible needs. The processing stage is supported by powerful computing units, which are available today. Processing usually aims to store, archive, manage, visualize, present and publish the collected data and the information derived. In the recent years many research efforts are directed to multi image matching techniques, thus complementing terrestrial laser scanning technology.

\subsubsection{Geoinformatics}

This interaction of heritage objects with their geographic location, is a well-known fact nowadays. It has bridged Geoinformatics and Monument Preservation. Geographic Information Systems (GIS) is the scientific tool with which monuments and related information has been connected to place. In this way the Monument Information Systems (MIS) have evolved. However, the relation of intangible information with tangible Cultural Heritage is highly important and definitely required. Hence intangible Cultural Heritage may be linked to location, while at the same time important attributes of both forms of Cultural Heritage are preserved and interrelated.

\subsection{CHIMS}

Management of Cultural Heritage assets, tangible or intangible, is a domain in which the Information and Communication Technologies (ICT) are being extensively implemented. Hence, the Cultural Heritage Information Management Systems (CHIMS) have been developed. These Systems usually include the geographic reference of the items in the data base, i.e. their exact location using Geographic Information Systems (GIS) technology. Cultural Heritage Information Management Systems are gradually gaining in popularity and use among the specialists responsible for the curation of the cultural heritage assets, i.e. archaeologists, restorers, historians etc. Consequently a number of such systems have been already developed and are implemented sometimes even via the web (Agapiou et al. 2008, Foote \& Lynch 2011).

\section{SELECTED EXAMPLES}

In order to highlight the above presented approach, several characteristic examples of pertinent implementations are briefly presented in the following sections.

\subsection{D from 3D}

The implementation of almost entirely image based contemporary techniques for the three dimensional geometric documentation of the Tower of the Winds in Athens led to the production of a detailed textured 3D model. The resulting point cloud has been georeferenced and subsequently the surface, i.e. the mesh was created. Finally the three dimensional model was produced. In this way, the geometric documentation drawings, i.e. the horizontal section plans, the vertical section plans and the elevations, which include orthophotos of the monument, are being produced at will, for the complete geometric documentation.

The textured point cloud was produced and used as the source from which all required two dimensional drawings have been produced. These drawings traditionally include on one hand a specific section line representing the section of the monument with the horizontal or vertical plane on which all details should be orthogonally projected and these details on the other. In this case the details were extracted from the orthogonal projection of the three dimensional textured model on the specific plane each time. The innovative approach in this case is that all necessary data were extracted from the image based 3D model.

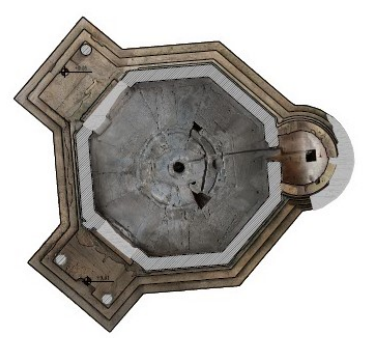

(a)

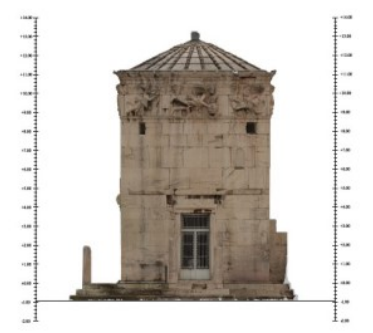

(c)

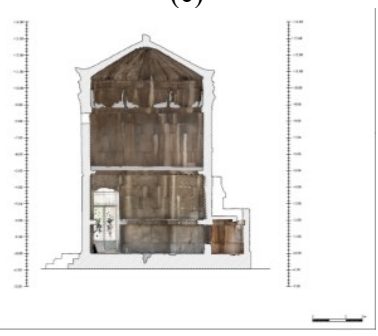

(e)

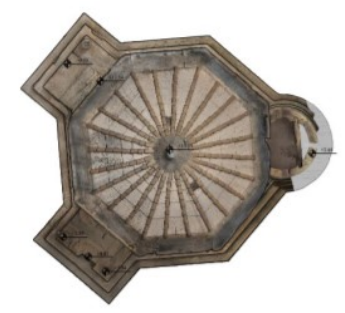

(b)

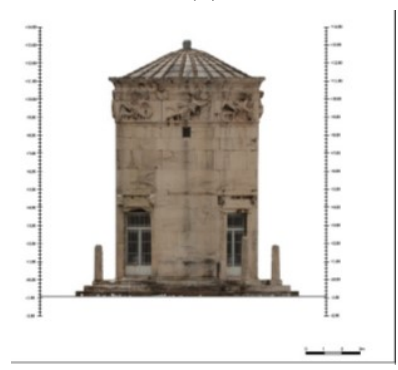

(d)

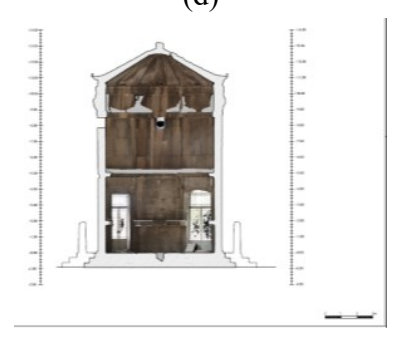

(f)
Figure 1: Samples of the final drawings. A horizontal section (a) and the bird's eye view of the roof (b), tow outside elevations (c) and (d) and two vertical sections (e) and (f) 
For the complete geometric documentation of the Tower of the Winds, 20 drawings were produced. In Figure 1 some representative samples of these products are shown. These drawings contain all the necessary information in form of raster images, i.e. the orthophotos. Consequently they are complete and in fact they contain more information than necessary for any kind of application. This means that they could serve as a basis for producing further specific products e.g. line drawings of the pathology or of the geometry or of the materials used etc. However, this requires the careful interpretation by the interested experts each time. If further drawings are required, e.g. additional horizontal sections or elevations, they may easily be produced from the three-dimensional texture model in the same way. In that sense the approach implemented is efficient and offers ease of production for further geometric documentation products.

\subsection{Structural Studies}

The Kapnikarea chapel (Figure 2) is located in the historical centre of Athens, in the middle of a pedestrianised zone at the edge of the Plaka district. The chapel is dated to the 11th century (1050 - 1075 A.D.) and it belongs to the cruciate enrolled type with cupola, which means that it is a complex, four-columned, cross-in-square church. The restoration of Byzantine Churches in Greece is essential for the preservation of a large and historically important part of the Greek cultural heritage. There are over 250 Byzantine Churches across the country and twenty-five alone, in Athens, following the same architectural type as the Kapnikarea Chapel. Therefore, the understanding of the structural behaviour of the Kapnikarea and its insidious deterioration will be a determinant step forward for the understanding of other historical structures, which is an essential piece of information for adopting a critical and economical conservation scheme for this Byzantine Heritage. Kapnikarea Chapel was chosen for this study, not only due to its exposure to continuous vibrations, but also due to the fact that it is the only church in the country which belongs to the University of Athens as it is a natural laboratory for the students of Theology and Byzantine painting. A complete analysis of the church's structural behaviour would cover continuous monitoring of the structure, due to different aspects, i.e. airpollution, vibrations generated by trains, vehicles, etc. However, this study aims to provide a prediction of its structural behaviour through modal analysis.

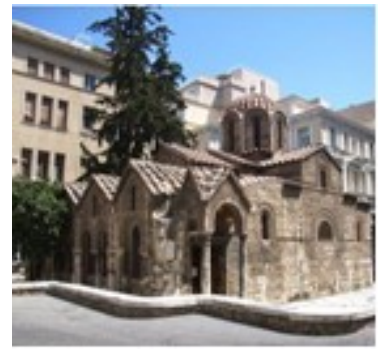

Figure 2: The Kapnikarea Chapel

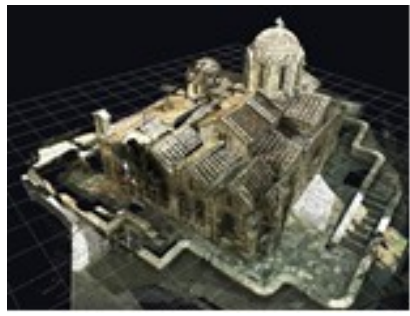

Figure 3: The 3D textured model
Underground metro trains pass between Syntagma and Monastiraki stations $19 \mathrm{~m}$ beneath the chapel. The Athens underground railway project was designed in 1986 and its construction works started in April 1994. In May 1999, the tunnel boring started from SYNTAGMA towards MONASTIRAKI using conventional methods, i.e. a tunnel boring machine (TBM). More than two years later, in September 2001, the construction had been completed. Finally, in April 2003, the trains over that section started running.

However, during the construction works of the Metro system beneath the chapel and based on the extensive monitoring measurements which were taken during that period $(01 / 09 / 2000$ - 15/10/2001), it had been noticed that a vertical settlement of up to $10 \mathrm{~mm}$ had occurred. All these aspects which have the potential to alter the structural behaviour of the Church; the tunnel's excavation method, the existence of underground voids, the potential impact of water and how all these reasons might behave during an earthquake or under the continuous vibrations generated by the passing tube trains, are technical questions which require a continuous monitoring record of the church and an experienced multi-disciplinary team, in order to provide sufficient answers. However, a key issue that requires new research is an understanding of the influence of the structure due to continuous vibrations and how this may cause deterioration in time.

For that purpose, it was decided to scan the chapel, in order to obtain its point cloud and 3D model (Figure 3), by which the solid 3D model (Figure 4) of the structure, which was created using the Revit2010 drawing software, would be able to be inserted into the ABAQUS software initially for modal analysis and later on for structural analysis. The equipment that was used was a time-of-light terrestrial laser scanner, Leica ScanStation 2 (Metheniti et al. 2012).

The chapel's 3D solid model, created in Revit2010, was inserted into ABAQUS v.611 (Figure 5). 72 parts were automatically created which were joined together using the assembly command. The material's properties were defined in order to perform under linear elastic behaviour. Fixed end constraints were assigned at fifty different positions of the chapel's floor, four of which were at the four corner bottom edges of the model.

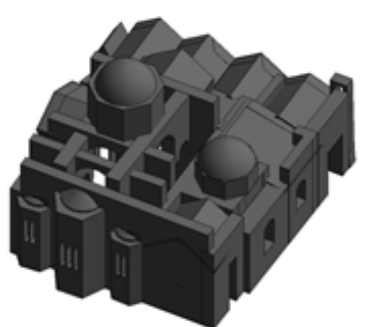

Figure 4: The solid 3D model

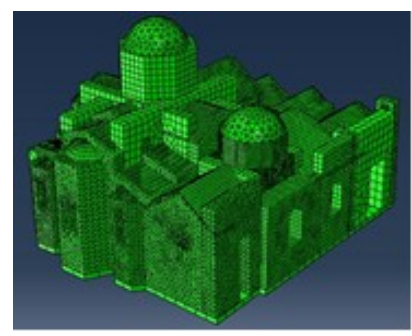

Figure 5: The ABAQUS model
The first mode's frequency of $1.1 \mathrm{~Hz}$, is not able to provide us with sufficient outcomes about the structural behaviour and deterioration of the Kapnikarea Chapel; further analysis for computing sufficient outcomes need to be carried out. In addition, push-over and time-history analyses will be performed in order to check if the chapel is able to withstand again a similar earthquake as the one occurred in Athens in 1999 and finally, the 3D solid model will be drawn at higher level of architectural accuracy. 


\subsection{Virtual Museums}

Developing and displaying a museum in a virtual environment has some advantages especially concerning the preservation and promotion of cultural heritage but also the development of tourism and the promotion of the touristic product. Virtual museums are important to both the visitors and the museums themselves and their curators. The majority of the museums only exhibit a small part of their collection due to the lack of space and of course due to the fact that some objects are extremely valuable or fragile (Lepouras et al., 2004). In a virtual and interactive environment the visitor is able to interact with the digitised exhibits and learn all the essential, historical information about them. Moreover, in a virtual environment the visitor can view a virtual reconstruction of important objects, buildings and archaeological sites that may no longer exist are damaged or access to them is not permitted. Moreover collections may also be displayed made of objects that are spread in various museums around the world.

The digitisation of cultural heritage helps to preserve, store, renew, retrieve and make it accessible for a wider audience in a more appealing and contemporary way, especially to people with special abilities or people that may never have the chance to visit the real museum (Sylaiou S. et al., 2009). The wide use of internet, social media and websites can make the digitised content of a museum more accessible and transport it to everyone all around the world. It is important to mention the result of the Colorado's University research according to which $70 \%$ of a total of 223 million people who visit a museum website would subsequently be more likely to go and also visit the real museum (Griffiths J.M., King D.W., 2007). This means that the virtual museum functions in a complementary manner to the real museum. Finally, in virtual museum exhibitions the visitor is able to fully control the navigation as well as to freely explore, move around, manipulate the exhibits and create his/her own, unique virtual experience or collection of $3 \mathrm{D}$ digital exhibits even from different museums. It is obvious that every effort and innovation that concerns the digitisation of cultural heritage and the development of virtual museums and applications is a complicated, difficult, controversial task with many advantages and can only benefit and offer both the museums and the visitors. Especially in Greece, $65 \%$ of the tourists make an online search of their destination and $45 \%$ of them are interested in cultural heritage, monuments, museums and archaeological sites.

The Virtual Museum of the Stoa of Attalos is an application where the visitor is able to make a tour in the museum on his own, explore it, interact with the exhibits, rotate them and learn all the necessary information about them. The development of this application took into consideration various aspects such as the requirements' analysis, the architectural design, the planning of the exhibits' presentation, the user interaction, the programming process and the evaluation of the final product (Lepouras et al., 2004).

As far as the Virtual Museum of the Stoa of Attalos is concerned, the virtual environment hosts some of the exhibits which can be found on the ground floor of the Stoa of Attalos, in the Ancient Agora of Athens. For this project, 16 of the exhibits were chosen from the south part of the colonnade of the museum and the most important concern was to produce accurate, realistic and appealing 3D models that can be used in virtual applications, especially in a short period of time. That is why photogrammetric methods and $3 \mathrm{D}$ surveys were used for the mass production of the exhibits' 3D models and the development of the virtual museum. In order to process the data and build the accurate, textured 3D models of the exhibits PhotoScan Professional ${ }^{\circledR}$ v.1.1 software by Agisoft was used.

The application is available in Greek and English. In the beginning of the virtual tour the visitor has the chance to read the instructions that are available in order to freely navigate in the environment and understand the options and opportunities he/she has in the virtual museum (Figure 6). The parameters that concern the movement, speed, rotation, height vision and behaviour of the visitor were extremely important in order to make the navigation friendly and easy for the visitor, as the majority of them may not have any previous experience with this kind of applications or even with the use of computers.

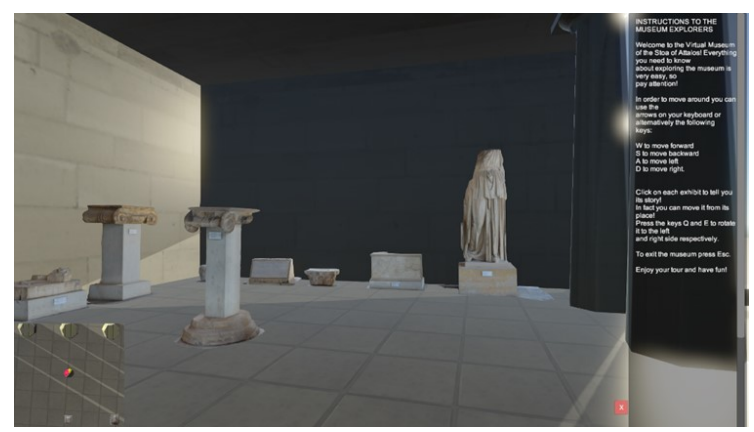

Figure 6: The environment of the virtual museum

Moreover, the ambience and the depth of field were properly adjusted in order to have a more clear and realistic view of the exhibits, which is also important to the visitor and his/her virtual experience in the museum. The visitor has the chance to learn and find out more information about the exhibits that attract and interest him/her simply by clicking on them (Figure 7). Moreover, the visitor is able to rotate the exhibits while the panel with the information appears on the right part of the screen. In that way the visitor is able to manipulate, closely examine and observe the details of every exhibit and at the same time learn not only the available information of the small panel that exists in the real museum, but also further information about it. The curator of the museum has the opportunity to choose the information that will be available to visitor and this is one of the advantages of this kind of applications. Finally, the last element that was added in the virtual environment was a mini-map to help the visitor move around and navigate in the environment without feeling disorientated, simply by offering $\mathrm{him} / \mathrm{her}$ a view of the virtual museum from the top (Georgopoulos et al. 2016).

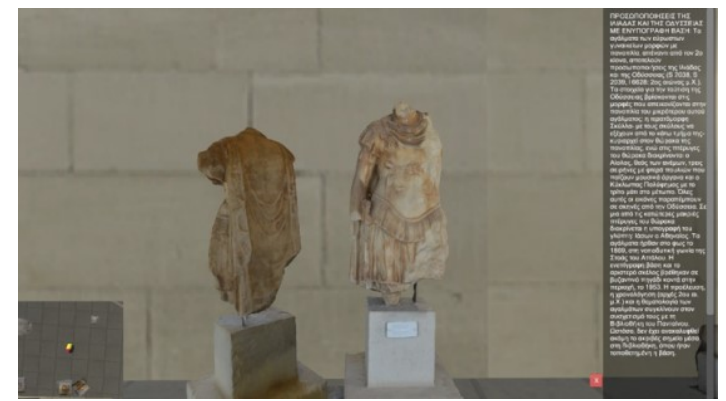

Figure 7: The virtual museum with all included elements 


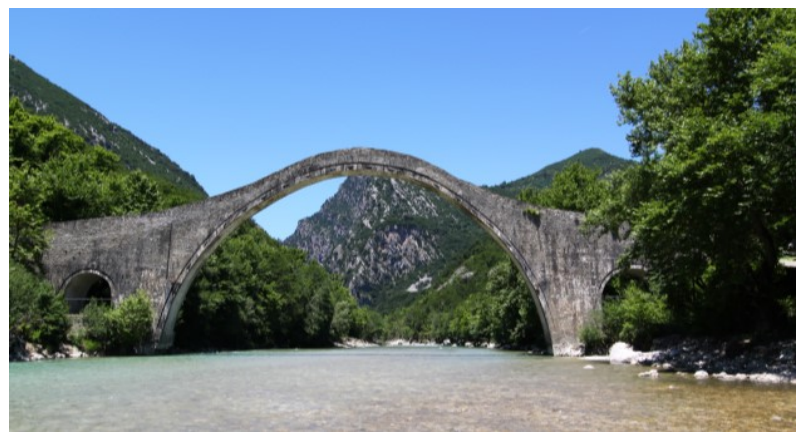

\subsection{Virtual Restoration}

The monument of Zalongon is situated on top of an $80 \mathrm{~m}$ high and steep cliff about $30 \mathrm{~km}$ north of Preveza. The sculpture is about $18 \mathrm{~m}$ long and $15 \mathrm{~m}$ high and is a composition of several female figures. Although fairly recent, the sculpture has suffered severely from frost and strong winds and tourists inscribing their names on the monument's surface. For its complete restoration a detailed and accurate geometric documentation and a three dimensional model of the construction were required. Given the size and complexity of the monument, contemporary digital techniques were employed for this purpose (Valanis et al. 2009).

The most interesting product, possible only with the use of contemporary digital methods, was the 3D model. For the creation of the surface of the 3D model all of the original scans were registered into a common reference system by applying a method that was specially developed. The creation of high resolution textured 3D models is undoubtedly a non-trivial task
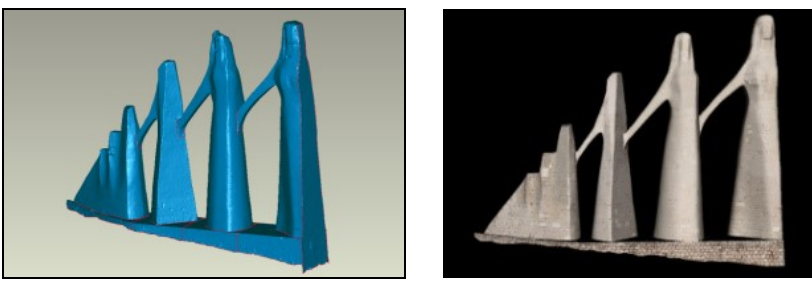

Figure 8: Virtual restoration of the Zalongon monment as it requires the application of advanced data acquisition and processing techniques, such as geodetic, photogrammetric, scanning, programming, surfacing, modelling, texturing and mosaicking.

For achieving restoration, the basic steps are: identifying the destroyed parts, interact with the 3D model and extract the geometry of the parts to be restored, insert them virtually into the 3D model and finally assess the result, before final decision. In the present case the main points of interest were of course the destroyed figure heads, but there were also many other damages to be restored (Figure8).

\subsection{Lost Heritage}

A variety of arched stone bridges exist in the Balkan area, built mainly in the 18th and 19th centuries or even earlier. Such structures were built for pedestrian and animal passage, as the rivers did not allow easy crossing, especially during winter (Leftheris et al., 2006). In the pre-industrial era, the main structural material in the Balkan region was the local stone. In Epirus, limestone and wood was commonly used by specialized technicians for such purposes. Stone bridges constituted a wide trail network for communication and transportation in the whole Balkan area.

The stone bridge of Plaka over river Arachthos (Figure 9) was a representative example of the aforementioned monuments. It was built in 1866 by local Greek stonemasons in order to facilitate transportation and trade needs. It was the widest stone bridge in the area of Epirus with 40 meter span and the biggest single-arch bridge in the Balkans with a height of 20 meters Next to the main arch there were two smaller relief arches 6 meters wide.

Apart from its significant size and age, the stone bridge of Plaka was a renowned stone bridge in Greece because of its emblematic historic meaning. Firstly, it was the border between free Greece and the occupied part of Greece by the Ottoman Empire between 1881 and 1912. During World War II the bridge was bombed by the German army with partial damages. At the same period, representatives of the various armed groups of Greek Resistance signed the Treaty of Plaka on this very bridge.

On the February 1st 2015, the central section of the bridge's arch collapsed due to extreme weather conditions namely massive flash floods caused by prolonged heavy rainfall. Most of the collapsed parts lie in the river area near the abutments that remain intact (Figure 10). NTUA has immediately initiated voluntary actions to aid in the eventual reconstruction of the stone bridge. In this project an interdisciplinary group of scientists and engineers will contribute.

The type of eventual reconstruction in the current study is under discussion. Before the implementation of any actions, a thorough geometric documentation is necessary, as clearly dictated by the Venice Charter. For that purpose the Laboratory of Photogrammetry undertook two tasks (a) to produce digital three dimensional drawings from a documentation study conducted in 1984 using traditional surveying techniques (Karakosta et al., 1984) and (b) to produce a textured three dimensional model of the Plaka Stone Bridge in order to geometrically document its shape and size before the collapse. This 3D model would be produced from existing images taken by visitors of the bridge over the years. These documentation products will form the basis for any eventual reconstruction study. Unfortunately, no earlier photogrammetric documentation is known to exist so far.

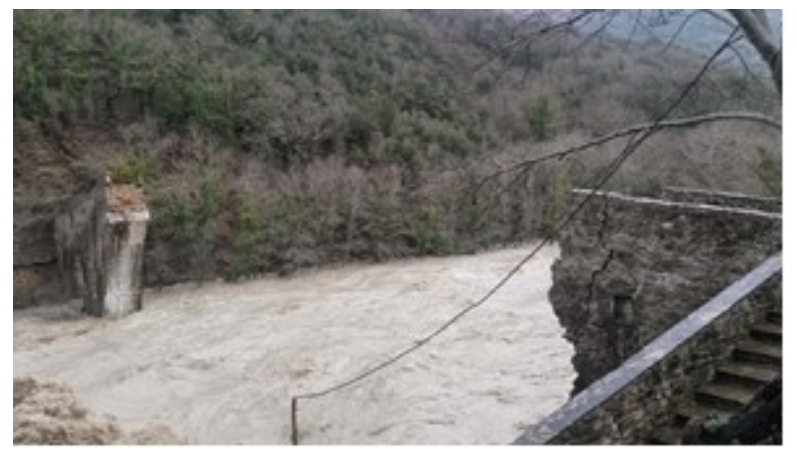

Figure 10: The remains of the bridge after destruction (http://epirusgate.blogspot.gr/2015/02/blog-post_32.html)

The majority of the collected images are of high resolution, correctly focused and without significant perspective or optical distortions. Nevertheless, in crowdsourcing applications the 
data may not meet the requirements of the scope for which they were collected. In this case study the authors have had to cope with some special challenges. A great percentage of the images were acquired from a viewpoint very close to the object and cannot, thus, be registered to the rest using the available algorithms. Large illumination variations due to natural light (bright sunshine, clouds, shadows, dusk light etc.) appear in several photos. Apart from that, the images that are suitable for the specific purpose of the project show significant variations on the bridge's surface due to seasonal effects. During summer months the stones are dry, in winter they appear darker and wet, with black grey crust and growing grass, thus complicating the location of point correspondences. Trees and other natural or human obstacles hinder important information. The geometry of the bridge, which is almost symmetrical, makes it difficult to distinguish between the north and the south façade. The majority of the collected photos were taken facing upstream and mainly from the east riverside due to landscape inaccessibility. This causes gaps and difficulties for the algorithm to converge to a stable geometry. After a thorough and careful sorting, it was established that less than 60 images fulfil the needs of the project in terms of viewpoint, image resolution, lighting conditions, occlusions etc., which corresponds to $10 \%$ of the total contributions.

The selected data have been processed using commercial as well as free software. VisualSfM is a free GUI application for 3D reconstruction that implements SfM and PMVS along with other tools (Wu, 2007; Wu et al., 2011; Wu, 2013; Furukawa and Ponce, 2010, Furukawa et al., 2010). In our case study, a dense point cloud was produced by 51 images (Figure 11). A mesh has also been created, followed by the texturing procedure (Figure 12).

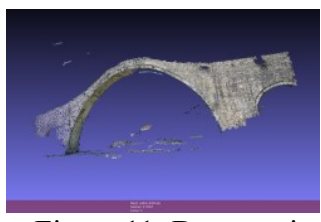

Figure 11: Dense point cloud after PMVS software

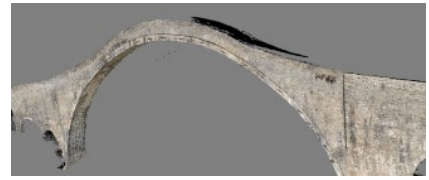
textured mesh
Figure 12: A view of the

The progress so far of an on-going project that aims to produce $3 \mathrm{D}$ textured models of the stone bridge of Plaka that suffered sudden loss has been presented. As data for a complete 3D reconstruction do not exist, a 3D representation of the bridge using crowdsourced images is the only way to preserve the memory and help towards its eventual reconstruction. A crowdsourcing platform has been designed and commercial as well as free 3D reconstruction software has been used to this end. Preliminary results demonstrate the robustness of the state of the art algorithms that are able to register together images of high diversity and create usable 3D models. These preliminary models may not be complete yet, but serve adequately as a base for future work, visualisation and educational purposes. It is also estimated that further exploitation of more images uploaded will result to a usable geometric documentation record for the eventual reconstruction (Stathopoulou et al. 2015).

It should be stressed that the wide promotion of the $3 \times 3$ Rules proposed by CIPA (Waldhaeusl and Ogleby 1994), which stands for Committee Internationale de Photogrammetrie Architecturale, and revised in 2013, available at the relevant webpage (www.cipa.icomos.org) would ensure the existence of more useful images and related metadata for the Plaka Stone Bridge, as the public would be more aware of the eventual future significance of their souvenir images. The $3 \times 3$ rules, dictate how a monument could be documented in a simple was by following 3 rules for taking the field data, 3 rules for using the camera and 3 rules for recording the metadata. This may be useful in the future for other monuments in similar situations.

\section{CONCLUDING REMARKS}

The purpose of this paper was to shed light on the three dimensional documentation of Cultural heritage objects and their use. It is believed that objects like these, should be geometrically documented in $3 \mathrm{D}$ for their preservation, but also for further use. As it has been demonstrated, these further uses may include structural studies, support of virtual or actual restorations and realization of remote visits. These further uses may only be limited by imagination, as the advancement of contemporary data acquisition and processing technologies is helping experts to easily produce realistic results.

\section{REFERENCES}

Agapiou, A., Georgopoulos, A., Ioannides M. \& Ioannidis C. 2008. 'A web based GIS for the byzantine churches of Cyprus', In VSMM 2008 - Conference on virtual systems and multimedia dedicated to digital heritage, pp. 148-151. 20-25 October 2008, Project Papers Volume. http://www.byzantinecyprus.com/refe rences/publications/53-a-web-based-gisfullpapercorr/download.html.

Foote, K. \& Lynch, M. Geographic information systems as an integrating technology: context, concepts, and definitions. http://www.colorado.edu/geography/gcraft/notes/intro/intro_f.ht $\mathrm{ml}$.

Furukawa, Y., Ponce, J. (2010). Accurate, dense, and robust multiview stereopsis. Pattern Analysis and Machine Intelligence, IEEE Transactions on, 32(8), 1362-1376.

Furukawa, Y., Curless, B., Seitz, S. M., Szeliski, R. (2010). Towards internet-scale multi-view stereo. In Computer Vision and Pattern Recognition (CVPR), 2010 IEEE Conference on (pp. 1434-1441). IEEE.

Georgopoulos, A., Kontogianni, G., Koutsaftis, Ch., Skamantzari, M., 2016. Serious Games at the Service of Cultural Heritage and Tourism. Proceedings IACUDIT Conference, May 2016, Athens (to appear in International Journal of Cultural and Digital Tourism).

Griffiths, J-M., King D.W. (2007). Physical Spaces and Virtual Visitors: The Methodologies of Comprehensive Study of Users and Uses of Museums, in International Cultural Heritage Informatics Meeting (ICHIM07): Proceedings, J. Trant and D. Bearman (eds). Toronto: Archives \& Museum Informatics. Published October 24, 2007 at http://www.archimuse.com/ichim07/papers/griffiths/griffiths.ht $\mathrm{ml}$

Karakosta, E., Papanagiotou, B., Tragaris, N., Chatzigeorgiou, Th., Arampatzi, O., Doggouris, S., Mpalodimos, D-D., (1984). Plaka Bridge: Survey- Check for vertical deformations, Diploma Thesis, National Technical University of Athens. 
Leftheris, B.P., Stavroulaki, M.E., Sapounaki, A.C., Stavroulakis, G.E., (2006). Computational Mechanics for Heritage Structures, WIT Press, Southampton.

Lepouras G., Katifori A., Vassilakis C., Haritos D. (2004). Real Exhibitions in a Virtual Museum. Archives of Journal of Virtual Reality, Vol.7, Issue 2, pp. 120-128.

Metheniti, M., Kalinyktakis, A., Georgopoulos, A., 2012. Terrestrial laser Scanning for Monitoring a Historic Byzantine Church. Proceedings of 8th International Conference on Structural Analysis of Historic Constructions, SAHC 2012. October 15-17, Warsaw, Poland.

Stathopoulou, E. K., Georgopoulos, A., Panagiotopoulos, G., Kaliampakos, D., 2015. 3D Visualisation of Lost Cultural Heritage Objects Using Crowdsourcing The International Archives of the Photogrammetry, Remote Sensing and Spatial Information Sciences, Volume XL-5/W7, 2015 25th International CIPA Symposium 2015, 31 August - 04 September 2015, Taipei, Taiwan.

Stylianidis, E., Remondino, F. (eds), 2016. 3D Recording, Documentation and Management of Cultural Heritage. Whittles Publishing, ISBN 978-184995-168-5, pp. 388.

Sylaiou S., Liarokapis F., Kotsakis K., Patias P. (2009). Virtual museums, a survey and some issues for consideration. Archives of Journal of Cultural Heritage, Elsevier, 10, ISSN: 1296-2074, pp. 520-528.

U.N.E.S.C.O., 1972. Photogrammetry applied to the survey of Historic Monuments, of Sites and to Archaeology. UNESCO editions.

Waldhäusl, P., Ogleby, C. L. (1994). 3 x 3 rules for simple photogrammetric documentation of architecture. International Archives of Photogrammetry and Remote Sensing, 30, 426-429.

$\mathrm{Wu}, \mathrm{C}$. (2013, June). Towards linear-time incremental structure from motion. In $3 D$ Vision- $3 D V$ 2013, 2013 International Conference on (pp. 127-134). IEEE.

Wu, C., Agarwal, S., Curless, B., Seitz, S. M. (2011, June). Multicore bundle adjustment. In Computer Vision and Pattern Recognition (CVPR), 2011 IEEE Conference on (pp. 30573064). IEEE.

Wu, C., "SiftGPU: A GPU implementation of Scale Invariant Feature Transform (SIFT)", http://cs.unc.edu/ ccwu/siftgpu, 2007.

Valanis, A., Tapinaki, S., Georgopoulos, A., Ioannidis, C. 2009. High Resolution Textured Models for Engineering Applications. Proceedings XXII CIPA Symposium, Oct. 11-15, 2009, Kyoto, Japan. 